\title{
Certifying achievement in the control of Chagas disease native vectors: what is a viable scenario?
}

\author{
Ken Hashimoto ${ }^{1,2} /{ }^{+}$, Kota Yoshioka ${ }^{3}$ \\ ${ }^{1}$ Takemi Program in International Health, Harvard School of Public Health, Boston, MA, USA \\ ${ }^{2}$ Former Regional Adviser for Chagas Disease Control in Central America \\ ${ }^{3}$ Former Expert for Chagas Disease Control Project in Nicaragua, Japan International Cooperation Agency
}

\begin{abstract}
As an evaluation scheme, we propose certifying for "control", as alternative to "interruption", of Chagas disease transmission by native vectors, to project a more achievable and measurable goal and sharing good practices through an "open online platform" rather than "formal certification" to make the key knowledge more accumulable and accessible.
\end{abstract}

Key words: Chagas disease - vector control - interruption of transmission - control of transmission - certification

The recent papers by Abad-Franch et al. (2013) and Salvatella et al. (2014) discussed the approach for certification in the control of Chagas disease native vectors, referring to the situations in South America. We consider that most of the arguments are relevant and timely also for Central America. With intensions to enrich the discussions held so far principally from scientific and political viewpoints, we will be providing the third dimension, an operational perspective, based on the experiences from the control of Triatoma dimidiata in Central America. The term "operational" in this paper is expected to denote technical and financial practicality for low-budgeted countries to combat this neglected tropical disease.

After successful vector control interventions against Rhodnius prolixus, $T$. dimidiata became the main vector of Chagas disease in Central America (Cedillos et al. 2012, Hashimoto \& Schofield 2012, IPCA 2012). T. dimidiata with the origin in Peninsula of Yucatan in Mexico and Guatemala is found extensively from sylvatic to domestic areas throughout the region (Bargues et al. 2008). The vector has been reported in 21 of 22 departments in Guatemala, 14 of 14 departments in El Salvador, 13 of 18 departments in Honduras and 15 of 17 departments in Nicaragua (Tabaru et al. 1999, JICA 2014a).

Guatemala, El Salvador, Honduras and Nicaragua implemented vector control interventions with technical assistance of Japan International Cooperation Agency (JICA) since 2000 and made a notable progress in the control of T. dimidiata (JICA 2014a). The initial target set by the Initiative of the Countries of Central America for Control of Vector-Borne and Transfusional Transmission of Chagas Disease (IPCA) was to reduce the house infes-

doi: $10.1590 / 0074-0276140251$

+ Corresponding author: hashimok@gmail.com

Received 15 July 2014

Accepted 8 September 2014 tation index of $T$. dimidiata to below $5 \%$ (PAHO 2002). Recently few departments report over $5 \%$ according to the countries' presentations in IPCA annual meetings: two in Guatemala, four in El Salvador, five in Honduras and two in Nicaragua, though these data are not statistically representative (IPCA 2012, IPCAM 2013).

The reduction of house infestation index owes primarily to the indoor insecticide spraying; however, persistent reinfestation of $T$. dimidiata is observed in certain endemic areas even after multiple cycles of insecticide spraying (Hashimoto et al. 2006, 2012). Such repeated reinfestation implies that the risk of vector-borne transmission remains as threat to the population. Effectively, acute Chagas cases are sporadically, but continually reported from different parts of Central America including from those intervened (JICA 2014a, Sasagawa et al. 2014).

Due to the recurrent transmission risk, the core control strategy have shifted from massive insecticide spraying (attack phase) to entomological surveillance and selective response (surveillance phase). In the four Central American countries, the Ministries of Health have implemented community-based surveillance and response systems in order to address vector reinfestation with limited human and financial resources under decentralised health systems (Hashimoto \& Yoshioka 2012, JICA 2014a). For example, the Nicaraguan Ministry of Health through the surveillance response system received vector reports from 1,495 households in the northern five departments from July-December in 2013. As response, the local health personnel visited 1,293 (86.5\%) households to provide preventive education. Among them, 443 households were categorised as eligible for insecticide spraying and 318 (71.8\%) were sprayed by institutional vector control personnel or trained community volunteers (JICA 2014b).

Under the circumstance described above, the goal of T. dimidiata control has been a point of discussion again. The sub-regional initiative in the annual meeting of 2013 recommended that the "interruption of Trypanosoma cruzi transmission by T. dimidiata in human dwellings" would be a renovated objective (IPCAM 2013). The interruption is defined as zero seroprevalence among chil- 
dren aged between one-15 years old (optionally the target age could be between $0-5$ years old). The entomological information could be a reference, but not determinant, to demonstrate the interruption of $T$. cruzi transmission. Achievement of the following indicators is encouraged: (i) combined indoor and peridomestic infestation index to be lower than $5 \%$, (ii) indoor infestation index reduced to less than $2 \%$ and (iii) more than $50 \%$ of reduction in the percentage of infested villages or dispersion index at municipality level (IPCAM 2013). Apparently, these criteria derive from experiences of vector control in South America, where the interruption of transmission was technically achievable in most parts. However, some closer speculations may be necessary to adapt the criteria to the control of $T$. dimidiata in Central America.

To deliberate upon the interruption of $T$. cruzi transmission by native vectors, the arguments of Abad-Franch et al. (2013) and Salvatella et al. (2014) marked important implications. We consider that fundamental concepts are shared between two sides in the discussion. Firstly, the operational interventions must be continued to minimise the infection risks. As the native vectors are not eliminable and could reinfest human dwellings, the entomological surveillance and response system must be sustained. Secondly, there is a need to reestablish a regional evaluation mechanism for the control of native species. Yet, since the existing framework was developed on the basis of experiences of controlling eliminable vectors, such as Triatoma infestans in major parts of South America and R. prolixus in Central America, its focus lacks in emphasis on sustainability of the control efforts.

So, how better can we certify the control of native vectors? What are the pros and cons of the certification? These are the central questions worth readdressing to.

Salvatella et al. (2014) maintain the standpoint that the traditional scheme of certifying the interruption of transmission of T. cruzi (CIT) should also be applied for the control of native species. Rationale for the CIT is the power of numbers. The CIT provides the countries with clear and common goals which may increase the governments' political will and financial resources. As Salvatella et al. (2014) repeatedly stress, the CIT in reality successfully produced positive impacts on the control of eliminable vectors in South and Central America. Indeed, the CIT organised by the subregional initiatives politically and technically facilitated the member countries in preparation of national strategic plans and involvement of donor agencies (JICA 2014a).

However, the CIT faces major challenges in Central America as an evaluation scheme for the control of T. dimidiata. Firstly, the CIT does not demonstrate improbability of further incidence after the certification. Even though a cross-sectional serological survey reveals zero seroprevalence of a particular moment, the result is hardly valid thereafter, because of persistent transmission risks presented by the native vectors. Certifying a temporal interruption is impractical in the control of native vectors. Secondly, it is extremely demanding for the Central American countries to obtain convincing evidence to show the interruption of $T$. cruzi transmis- sion. Because the native vectors are vastly distributed, the serological and entomological data must be collected from extensive geographical areas. The lower the target seroprevalence, the larger the sample size is required statistically to assure the representativeness. This implies considerably high cost and financial burden for the affected low-budgeted countries. Thirdly, the collected data may misguide the certification. As Abad-Franch et al. (2014) point out from the scientific view, the serological surveys are prone to bias due to underestimation of at-risk population, limited samples by targeting only children and usage of filter paper or diluted glycerin. These methods are also used in Central America. Similarly, with $T$. dimidiata, the entomological survey data could be biased because of unreported vectors and lack of sensibility in the vector search techniques (Monroy et al. 1998). Incomplete data analysis could certify apparent interruption of $T$. cruzi transmission. For these reasons, we consider that the CIT is not a suitable goal for the control of T. dimidiata in Central America.

The alternative by Abad-Franch et al. (2013) is to certify good practices (CGP) which could improve performance of control programs through detecting and correcting malfunctions. Abad-Franch et al. (2013) argues that the CGP would provide the countries with incentives to create ideas for problem solving and breakthrough, as well as operational images to improve program performance and quality control. In their view, the CGP benefits people at risk by strengthening control programs, while the CIT would benefit only health authorities. The CIT could weaken long-term control-surveillance systems, because the government can reduce the national budget after receiving certification, discontinue the operational activities and consequently suffer from reemergence of the new T. cruzi transmission.

From the operational perspective, we agree that the CGP could continuously improve the disease control programs. To sustain the surveillance and response systems for the native vectors, a variety of maintenance is required to overcome different challenges such as lack of financial and human resources, data quality and community participation. If the good practices are replicated along with Plan-Do-Check-Act (PDCA) cycle to resolve these operational difficulties, the CGP may increase effectiveness, efficiency and sustainability of the control efforts at different levels of the Ministry of Health (JICA 2014a). Nevertheless, the CGP may also bring about several challenges. Firstly, the CGP could emphasise the importance of the process improvement, but would not give a clear indication of overall progress or long-term achievement. Secondly, good practices are likely to be evaluated with more subjective and biased criteria than CIT. The judgment of "good" depends on the personal value, as well as how the criteria are established and interpreted by the evaluation mission. Thirdly, good practices tend to be context specific. Some practices could be unhelpful or even damaging in other circumstances. Moreover, the contexts are constantly changing. Proven but outdated practices may cause the curse of success. Such contextual peculiarity makes systematic evaluation rather complex and time consuming for both officials of 
the Ministry of Health and evaluation teams. In our opinion, the CGP could be too complex to gather momentum of the control efforts towards a common goal.

In practice, we consider that the countries require both result and process oriented evaluations for the native vector control. The CIT and CGP approaches are not contradictory, but rather synergic when integrated strategically. The long-term regional goals with evaluation provide clear direction and incentive to the countries, scientific communities and donors. Knowledge management focused on good practices will improve performance of the disease control activities. Hence, from the operational perspective, we suggest that a strategic scenario would be (i) to maintain the quantitative international certification system, but not for "interruption", and (ii) to create a more accessible knowledge management mechanism to facilitate sharing good practices.

Considering the persistent infection risks by the native vectors and limitations in demonstrating complete evidence with serological surveys, an operationally achievable point may be where Chagas disease transmission is controlled. By definition, "control" is "the reduction of disease incidence, prevalence, morbidity or mortality to a locally acceptable level as a result of deliberate efforts; continued intervention measures are required to maintain the reduction" (Dowdle 1998). The certification of control of transmission (CCT) as a regional goal would continue offering political incentives and long-term vision to the countries, but would avoid misleading both government and public towards discontinuation of the control efforts.

The CCT evaluation should require (i) seroprevalence among the children under 15 years old as the principal indicator and (ii) geographic coverage of surveillance on native vectors and acute cases as necessary conditions. When seroprevalence among the children is less than an established criterion, for example $1 \%$, the transmission can be considered as "controlled". The criterion is an arbitrary number in accordance with the local epidemiological situation. As the control makes progress, the target figure could be gradually refined and lowered. For the entomological and acute case surveillance, the higher the potential infection risk the greater the geographic coverage should be. The surveillance coverage should be complete at least at the high risk areas.

To implement the CCT scheme, we recommend to scale down the target geographic area from a country to a smaller political division such as department or province (Hashimoto \& Yoshioka 2012). This framework would facilitate organisation of evaluation activities in each country, by allocating limited resources to a particular area and by motivating the local personnel with a more achievable goal. Further, the country could generate a sense of competition among departments or provinces, which would stimulate the decentralised health systems to reinforce the control activities.

In view of sustaining the disease control efforts, the certification should be reversible (Hashimoto \& Yoshioka 2012). That is, the certification will be withdrawn, unless two essential requirements were fulfilled. One is that serological survey results should be presented to the subregion- al initiative on a regular basis (e.g., every 5 years), showing that the seroprevalence is less than the established criterion. The other is the sufficient coverage of entomological and acute case surveillance. The data should be collectable as part of routine surveillance activities and be presented at the annual meetings of the sub-regional initiative.

For data collection, we recommend to design the sampling method strategically, rather than statistically, to maximise the limited available resources. For example, the sampling areas may be classified into high, medium and low risks within a department or province, according to the previous epidemiological records. The idea is to collect more serological samples from the high risk areas, followed by medium and low risk areas. This strategy is statistically opposite of what is required to demonstrate low seroprevalence and, unlike stratified sampling, will not assure representativeness for each risk group. However, to approach substantial geographic area with limited resources, searching for recent infection cases in high risk zones becomes more efficient than proving low seroprevalence throughout a vast land. The risk-focused approach should also facilitate the government officials justify their evaluation plans, claiming that the budgets would be spent for the most needed.

To improve quality of data analysis and increment objectivity of the certification, Abad-Franch et al. (2013) point out the importance of peer-review on the country's report presented to the evaluation mission. From operational viewpoint, however, academia can contribute better to the Ministry of Health, if they become involved at the designing stage of serological surveys and preparation for the country's final report for CCT. When convincing evidence needs to be presented under limited resources, useful intellectual input would be highly appreciated.

For the process-oriented evaluation, exemplified practices may encourage knowledge creation, management and sharing, leading to improvement in the native vector control efforts. Instead of certifying good practices, a useful knowledge library should be established, where numerous different practices are archived in a concise and readily accessible manner. For instance, a simple online platform may be created for the public health practitioners to upload their good practices for the others to view. To augment participation, each practice can be evaluated by clicking on a "like" icon or a "five-star-scaled" button by the viewers. The sub-regional initiatives may provide a prize or recognition on a regular basis for the countries to have reported the most highly valued practices in the library. This knowledge management platform should also be administrated under the CCT mechanism.

In conclusion, the control of Chagas disease native vectors is an enduring challenge, where the subregional initiatives can greatly contribute to the countries' efforts by providing result and process oriented evaluations. We recognise the importance of the goals being achievable technically and financially and therefore propose the certification of "control of $T$. cruzi transmission" as alternative to the "interruption of T. cruzi transmission". To maintain Chagas disease controlled, the interventions must be constantly improved in the effectiveness, effi- 
ciency and sustainability. A key improvement strategy is integration of good practices into the health systems through the PDCA cycle. We agree on encouraging the knowledge management to create, replicate and share the good practices, but not by means of systematic evaluation with international missions, rather by implementing a more practical and accessible platform such as online library for the public health professionals.

\section{REFERENCES}

Abad-Franch F, Diotaiuti L, Gurgel-Gonçalves R, Gürtler RE 2013. Certifying the interruption of Chagas disease transmission by native vectors: cui bono? Mem Inst Oswaldo Cruz 108: 251-254.

Abad-Franch F, Diotaiuti L, Gurgel-Gonçalves R, Gürtler RE 2014. On bugs and bias: improving Chagas disease control assessment (Reply). In R Salvatella, P Irabedra, LG Castellanos, Interruption of vector transmission by native vectors and "the art of the possible”. Mem Inst Oswaldo Cruz 109: 122-130.

Bargues MD, Klisiowicz DR, Gonzalez-Candelas F, Ramsey JM, Monroy $\mathrm{C}$, Ponce $\mathrm{C}$, Salazar-Schettino PM, Panzera F, Abad-Franch F, Sousa OE, Schofield CJ, Dujardin JP, Guhl F, Mas-Coma S 2008. Phylogeography and genetic variation of Triatoma dimidiata, the main Chagas disease vector in Central America, and its position within the genus Triatoma. PLoS Negl Trop Dis 7: e233.

Cedillos RA, Romero JE, Sasagawa E 2012. Elimination of Rhodnius prolixus in El Salvador, Central America. Mem Inst Oswaldo Cruz 107: 1068-1069.

Dowdle WR 1998. The principles of disease elimination and eradication. Bull World Health Organ 76 (Suppl. 2): 22-25.

Hashimoto K, Álvarez H, Nakagawa J, Juarez J, Monroy C, CordónRosales C, Gil E 2012. Vector control intervention towards interruption of transmission of Chagas disease by Rhodnius prolixus, main vector in Guatemala. Mem Inst Oswaldo Cruz 107: 877-887.

Hashimoto K, Cordón-Rosales C, Trampe R, Kawabata M 2006. Impact of multiple residual spraying of pyrethroid insecticides against Triatoma dimidiata (Reduviiade: Triatominae), the principal vector of Chagas disease in Jutiapa, Guatemala. Am J Trop Med Hyg 75: 226-230.

Hashimoto K, Schofield CJ 2012. Elimination of Rhodnius prolixus in Central America. Parasit Vectors 5: 45.
Hashimoto K, Yoshioka K 2012. Review: surveillance of Chagas disease. Adv Parasitol 79: 375-428.

IPCA - Iniciativa de los Países de Centroamérica 2012. XIV Reunión de la Comisión Intergubernamental de la Iniciativa de los Países de Centroamérica (IPCA) para la interrupción de la trasmisión vectorial, transfusional y atención médica de la enfermedad de Chagas. Recomendaciones, 13-14 Nov 2012, Ciudad de Belice.

IPCAM - Iniciativa de los Países de Centroamérica y México 2013. XV Reunión de la Comisión Intergubernamental de la Iniciativa de los Países de Centroamérica y México (IPCAM) para la interrupción de la trasmisión vectorial, transfusional y atención médica de la rnfermedad de Chagas. Recomendaciones, 22-23 Oct 2013, Ciudad de México.

JICA - Japan International Cooperation Agency 2014a. Buenas prácticas en el control de la enfermedad de Chagas en Guatemala, El Salvador, Honduras y Nicaragua 2000-2014. Japan International Cooperation Agency. Tegucigalpa, Honduras. Available from: jica.go.jp/english/our work/thematic issues/health/c8h0vm00000111s7-att/study_inf_01.pdf.

JICA - Japan International Cooperation Agency 2014b. Proyecto para el fortalecimiento de las actividades de vigilancia y control de la enfermedad de Chagas en Nicaragua. Informe de evaluación final, Agencia de Cooperación Internacional del Japón/Ministerio de Salud de Nicaragua, Ciudad de Managua, 38 pp.

Monroy C, Mejía M, Rodas A, Rosales R, Horio M, Tabaru Y 1998. Comparison of indoor searches with whole house demolition collections of the vectors of Chagas disease and their indoor distribution. Med Entomol Zool 49: 195-200.

PAHO - Pan American Health Organization 2002. Taller para el establecimiento de pautas tecnicas en el control de Triatoma dimidiata, OPS, San Salvador, 36 pp.

Salvatella R, Irabedra P, Castellanos LG 2014. Interruption of vector transmission by native vectors and "the art of the possible". Mem Inst Oswaldo Cruz 109: 122-130.

Sasagawa E, de Aguilar AVG, de Ramírez MAH, Chévez JER, Nakagawa J, Cedillos RA, Kita K 2014. Acute Chagas disease in El Salvador 2000-2012 - Need for surveillance and control. Mem Inst Oswaldo Cruz 109: 256-258.

Tabaru Y, Monroy C, Rodas A, Mejia M, Rosales R 1999. The geographic distribution of vectors of Chagas disease and population at risk of infection in Guatemala. Med Entomol Zool 50: 9-17. 